\title{
Panorama económico del Perú en el contexto del COVID-19
}

\section{Economic overview of Peru in the context of COVID-19}

Wuily Franz Trujillo Figueroa

Universidad César Vallejo, Perú

wilfranztrujillo@gmail.com

iD https://orcid.org/0000-0002-7610-6130

Edmer Mendoza Briceño

Universidad César Vallejo, Perú

mbedmer@hotmail.com

(D) https://orcid.org/0000-0002-7452-737X

Recepción: 03/02/2021 | Aceptación: 23/04/2021 | Publicación: 10/05/2021

\section{Cómo citar (APA, séptima edición): \\ Trujillo Figueroa, W. F. y Mendoza Briceño, E. (2021). Panorama económico del Perú en el contexto del COVID-19. Innova Research Journal, 6(2), 240-254. https://doi.org/10.33890/innova.v6.n2.2021.1715}

\section{Resumen}

La investigación ha tenido como objetivo describir la variación de la tasa de interés, el tipo de cambio, las reservas internacionales netas, el producto bruto interno y las expectativas empresariales durante el periodo de pandemia originado por la COVID-19 y cómo influyó en la economía peruana en el contexto macroeconómico en comparativa con cinco años seguidos de variabilidad económica. El análisis se realizó bajo el enfoque cuantitativo, se aplicó el método descriptivo, en la recolección de datos se empleó la técnica de análisis documental con el apoyo de las memorias del Banco Central de Reserva del Perú y estadísticas de la economía peruana desde el año 2016 hasta agosto del 2020. Para el análisis de cálculo se utilizó el software estadístico SPSS 26.0. En ese contexto la tasa de interés varió entre 12.30 y 17.73 puntos porcentuales a diferencia del tipo de cambio que fluctuó entre 3.21 y 3.51 soles, asimismo las expectativas empresariales se situaron entre 21.5 y 61.0 puntos, también el producto bruto interno se movió entre -39.9 y 4.2 en porcentaje, finalmente las reservas internacionales netas evolucionaron entre 57,999 y 74,782 millones de dólares.

Palabras claves: tasa de interés; tipo de cambio; expectativas empresariales; política monetaria; COVID-19. 
Wuily Franz Trujillo Figueroa y Edmer Mendoza Briceño.

ISSN 2477-9024. Innova Research Journal (Mayo-Agosto, 2021). Vol 6, No. 2, pp. 240-254

\begin{abstract}
The research aimed to describe the variation in the interest rate, the exchange rate, net international reserves, gross domestic product and business expectations during the COVID-19 pandemic period and how it influenced the Peruvian economy in the macroeconomic context compared to five consecutive years of economic variability. The analysis was carried out under the quantitative approach; the descriptive method was applied, in the data collection the documentary analysis technique was used with the support of the reports of the Central Reserve Bank of Peru and statistics of the Peruvian economy since 2016 until August 2020. For the calculation analysis, the statistical software SPSS 26.0 was used. In this context, the interest rate varied between 12.30 and 17.73 percentage points, unlike the exchange rate that fluctuated between 3.21 and 3.51 soles, likewise business expectations were between 21.5 and 61.0 points, also the gross domestic product moved between -39.9 and 4.2 in percentage, finally the net international reserves evolved between 57,999 and 74,782 million dollars.
\end{abstract}

Keywords: interest rate; exchange rate; business expectations; monetary politics; COVID-19

\title{
Introducción
}

La pandemia originada por el virus SARS-CoV-2 causante del COVID-19 en el Perú y en la región se siente como un gran problema en materia económica especialmente en el territorio peruano que ha tenido que soportar varios meses de confinamiento en cuarentena total con medidas extremas en cuidados y prevención con campañas publicitarias lanzadas por el gobierno que ni aun así hace efecto en el avance del nuevo coronavirus, en ese sentido la economía en el Perú hasta el día de hoy muestra variaciones negativas y por consiguiente las expectativas en los principales indicadores económicos se encuentran afectados y es por ello que hacemos esta recopilación histórica que será parte del análisis en el futuro económico peruano.

En tal sentido en la región, el nuevo coronavirus se expandió rápidamente asimismo la OMS declaró al COVID-19 como pandemia mundial, en el territorio peruano el día 15 de marzo del año 2020 el gobierno del Perú declaró cuarentena total anunciando el primer caso del nuevo coronavirus la cual se extendió hasta día 26 de junio donde se suavizó la cuarentena con medidas estrictas de confinamiento total a la población con horarios reducidos, tránsito de personas y con el estado de emergencia que vivimos hasta estos momentos con cuarentenas focalizadas y restricciones de horarios de salidas a la calle (Bedford, Enria, Giesecke, y Heymann, 2020).

Además, las medidas que se emplean para tratar de controlar el nuevo coronavirus hacen efectos en la economía, observando los indicadores económicos de política fiscal y monetaria tanto en la producción reflejada en el índice porcentual del PBI como a los diversos índices económicos generados por el efecto de la no movilidad de las personas y el resultado del manejo respecto al trabajo no presencial y los diversos impactos que conllevan la inamovilidad (Deb, Furceri, D. ostry, y Tawk, 2020).

Debido a la desaceleración de la economía mundial causada por la COVID-19 en términos de comercio internacional y el desabastecimiento de insumos o bienes de consumo por la 
paralización de la producción de las empresas en todo el mundo tuvo como consecuencia escasez y alteración en los mercados de commodities que con el paso del tiempo se vuelven a estabilizar, pero la incertidumbre continua por efectos de nuevos rebrotes del virus (Mckibbin y Roshen, 2020).

De la misma forma los efectos por el nuevo coronavirus se sintieron en las economías de todos los países del mundo, en esa línea se realizaron estudios con encuestas de percepción con expertos en temas económicos y los investigadores sostuvieron que los grados de inversión se redujeron en sus países por efectos de la pandemia, es por ese motivo que todas las regiones en previsión se vieron afectados por una recesión con porcentajes históricos a la baja en movimientos de capitales en todo el año 2020 (Boumans, Link, y Sauer, 2020).

En ese contexto la investigación es totalmente descriptiva y se ubica dentro de las ciencias económicas en el campo de la política macroeconómica monetaria que es dirigida en el Perú por el Banco Central de Reserva (BCRP) con la finalidad de preservar la estabilidad económica, financiera siguiendo sus estrategias y metas para lograr equilibrio en las variables analizadas (BCRP, 2011).

Asimismo, la investigación presenta una justificación teórica porque se aporta un nuevo análisis de la economía del Perú frente a la pandemia mundial producida por el SARSCOV2 asimismo el estudio se puede ampliar a futuro con nuevos sucesos que se producirán por la reactivación económica post-pandemia como también el análisis servirá como ayuda de comprensión de la fluctuación en tendencia de las variables en el tiempo influenciadas por la COVID-19. También el análisis presenta una justificación práctica porque permitirá tener una mejor percepción de los indicadores económicos descritos por ser una recopilación histórica de lo que pasó y tener una mejor visión de cómo se comportarán las variables a futuro, en el uso los indicadores descritos son analizados constantemente para evaluar un criterio de riesgos y percepción sobre la economía peruana.

\section{Marco teórico}

En el contexto nacional, el impacto de la COVID-19 en las variables económicas por el efecto de las restricciones y cuarentena extrema sufrió retrocesos y fluctuaciones negativas, las medidas tomadas por el gobierno peruano entre los meses de marzo a junio del año 2020, además se observó un fuerte incremento en los niveles de desempleo e informalidad en el país que ya sufría con anterioridad estos problemas (Bar rutia, Sánchez, y Silva, 2021).

Además, el gobierno peruano con un decreto supremo habilitó la suspensión perfecta de labores para las empresas que no podían seguir operando por las condiciones desfavorables para poder generar ingresos y producción la cual afecta al PBI así también el gobierno otorgó financiamiento mediante la banca privada a las empresas con los créditos a mínima tasa de interés que se denominó Reactiva Perú (Delgado, 2020).

También el nuevo coronavirus ha causado una gran cantidad de pérdidas de vidas humanas, como también incrementó los niveles de pobreza por la paralización de actividades económicas de 
Wuily Franz Trujillo Figueroa y Edmer Mendoza Briceño.

ISSN 2477-9024. Innova Research Journal (Mayo-Agosto, 2021). Vol 6, No. 2, pp. 240-254

la población en general, asimismo se espera que las estrategias económicas tomen la iniciativa de ejecutar más políticas públicas de inversión para propiciar la pronta recuperación de los niveles óptimos de crecimiento económico (Huamán, 2021).

En el contexto internacional, por efecto de la pandemia mundial causada por el nuevo coronavirus surgida en la provincia china de Wuhan y expandida en todo el mundo, las economías que dependían de productos importados del país asiático u otro país y este asimismo dependiente de insumos generados en la región, este efecto hizo una gran desaceleración en el comercio internacional mundial por temor a ser contagiados por el nuevo virus COVID-19 y esto causó estragos en la velocidad del comercio entre países derivados por la cuarentena y demás efectos (Mc kibbin y Roshen, 2020).

En esa línea en tiempos de pandemia originado por el virus SARSCOV2 las restricciones de movilidad de las personas se restringió a nivel mundial y esto afecto a la economía como a los gobiernos locales que se vieron afectados por la no generación de ingresos impositivos en ese sentido el costo de encierro es alto para todos los actores económicos (Bonaccorsi, Pierri, Cinelli, Flori, y Galeazzi, 2020).

Igualmente, la incertidumbre en la economía generada por la pandemia mundial hizo que los mercados bursátiles mundiales se desplomaran por las expectativas negativas de los agentes económicos hacia las fechas ya sean futuras o actuales de una posible inmunización de la población en corto o largo plazo, la incertidumbre se apoderó de los inversionistas y el nerviosismo de apostar en un mercado determinado (Baker, Bloom, Davis, y Terry, 2020).

Asimismo el artículo se apoya en la teoría keynesiana formulada por John Maynard Keynes y descrita en la teoría general del empleo, el interés y el dinero, como sabemos en los años treinta y con los problemas en materia económica que se vivió en aquellas épocas sobre la inversión que recaía en los empresarios para apalancarse de dinero generado de ahorros de los excedentes de la propensión marginal a consumir de los consumidores y estos no siendo eficientes en el sistema bancario se buscó la intervención estatal para que inyecte capital vía inversión pública pero esto crearía inflación y subempleo, estas grandes depresiones económicas que se vivieron en el pasado lo tenemos en el presente con los temas de generar crecimiento económico ante los desequilibrios ocasionados por los tiempos de pandemia (Rivot, 2020).

En tal sentido describimos que la tasa de interés (TI) durante la cuarentena y hasta la actualidad fluctuó por el riesgo que corren los bancos ante los agentes deficitarios y como estos dan facilidades de retorno de dinero y como los bancos manejan su cartera pesada de exposición en pandemia, la tasa de referencia en el Perú se mantuvo a la baja con un record de tasa mínimo histórico de $0.25 \%$ como se sabe la TI es el porcentaje que paga un prestamista a un banco para obtener liquidez inmediata, el costo de oportunidad por tener efectivo es lo que pagan en porcentaje los que se apalancan de dinero obtenido de una entidad financiera (Pascal y Simon, 2020).

También las expectativas respecto al tipo de cambio (TC) en la economía peruana se observó desde la incertidumbre hacia la reactivación económica en proporción a la amenaza que sienten los agentes económicos por los efectos del nuevo coronavirus y las decisiones del gobierno 
y la política monetaria en cuanto a los agentes especulativos en la relación sol - dólar ya que el TC se mueve en una flotación sucia con intervención del banco central cuando ocurren depreciaciones o apreciaciones del sol en relación al dólar (Beckmann y Czudaj, 2017)

En ese sentido como sabemos las reservas internacionales netas (RIN) sirven para enfrentar cualquier problema externo o interno ya sea una tormenta de pánico, en el caso del nuevo coronavirus el gobierno peruano destinó un paquete de medidas de reactivación económica respaldándose en las reservas que en el mes de agosto 2020 superaban los setentaicinco mil millones de dólares y una de las RIN más grandes de la región en comparativa con los demás países, asimismo estas medidas estimulan hasta el día de hoy la caída de todos los indicadores económicos y como consecuencia de estas inyecciones de dinero la economía toma un grado de velocidad en inversiones, consumo, liquidez, etc. (Singh, 2020).

En consecuencia, a la presencia del nuevo coronavirus los datos estadísticos del producto bruto interno (PBI) se mostraron en caída de tendencia por acción de la cuarentena extendida por varios meses hasta el día de hoy con restricciones de horarios y salidas, como se sabe el PBI se relaciona con la producción nacional para todo bien exportable o consumido internamente (Lippi, Henry, Mattiuzzi, y Bovo, 2020).

En relación con las expectativas empresariales en el Perú cayeron a niveles históricos tomando como referencia el punto de equilibrio en el horizonte de 50 puntos como indicador principal de la situación actual en las encuestas de percepción, asimismo en otras economías realizaron lo mismo tal es el caso que también se veían despidos masivos por la incertidumbre a lo que vendrá en el futuro incierto en los costos variables como lo son pagos de planillas a corto plazo o pagos de alquileres a la vista, la situación actual del negocio hasta el día de hoy en la economía peruana no logra recuperar su punto de equilibrio de 50 puntos como mínimo, el nivel de optimismo y confianza a pesar de las intervenciones del gobierno con programas de crédito a intereses bajos para lograr variar los niveles de confianza empresarial óptimos (Bartik, Bertrand, Cullen, Glaeser, y Luca, 2020).

En ese contexto nos apoyamos en el glosario de términos del banco central de reserva del Perú para explicar las variables económicas descritas donde: (a) tasa de interés, es el porcentaje que pagan los agentes deficitarios para obtener dinero a la vista con un precio de costo de oportunidad el cual desembolsan en porcentaje a una entidad financiera. (b) tipo de cambio, es la paridad o valor de proporción de la moneda local con respecto a la moneda de transacción mundial, moneda de refugio o divisa como es el dólar. (c) las reservas internacionales netas (RIN) son todas las provisiones en monedas, billetes, valores de aceptación general, depósitos de valor de divisas a la vista, tenencias de oro y plata, entre otros medios de atesoramiento que tiene un país para garantizar la estabilidad económica ante cualquier shock o evento financiero causados por agentes internos o externos que pueda sobrevenir en largo o corto plazo. (d) el producto bruto interno (PBI) es la sumatoria en una etapa de tiempo del valor de los bienes y servicios finales producidos en un país. (e) las expectativas empresariales, son los índices de confianza que tiene un inversionista, emprendedor, empresario como percepción basados en diversos indicadores económicos respecto a su retorno de capital en relación a su inversión (BCRP, 2011). 
Concluimos este capítulo destacando que la investigación tiene como propósito general la descripción de las alteraciones de cinco variables macroeconómicas por causas de la COVID-19 tomando como datos históricos lo sucedido cinco años antes en comparativa de variabilidad con la actual situación económica peruana generada por la pandemia, remarcando énfasis en la política monetaria.

\section{Metodología}

La investigación se realizó bajo el enfoque cuantitativo y se usó el análisis estadístico para procesar la data histórica con números exactos, además se utilizó los datos de economía peruana en el análisis para describir la teoría a la que nos apoyamos en el estudio, donde la hipótesis se formuló y se delimito en la descripción (Ñaupas, Mejia, Novoa y Villagómez, 2011; Sánchez, Reyes y Mejia, 2018)

Asimismo, se aplicó el método descriptivo la cual detalla diversas situaciones, acontecimientos en el comportamiento de fenómenos que ocurrieron en un determinado tiempo y se analiza con diferentes técnicas de investigación (Hernández, Fernández y Baptista, 2014).

En ese contexto en el estudio se describe lo sucedido con cinco variables económicas las cuales son usadas con frecuencia en estrategias de política económica, en el análisis se reseña el planeamiento que hace el gobierno peruano para afrontar los tiempos de pandemia originada por la COVID-19 en relación a lo acontecido en fechas anteriores para llegar a una comparativa con la actualidad apoyándonos en la estadística descriptiva (Bernal, 2020).

También se usó la técnica de análisis documental la cual concentra la información que se obtuvo de la recolección de datos de las memorias de la economía peruana y BCRP DATA, las diversas técnicas de estadística como parte del procesamiento de datos para la medición. Asimismo, el análisis de documentos de recopilación para obtener números exactos que se aplicaron en la evaluación estadística de datos (Peña y Pirela, 2007; Dulzaides y Molina, 2004).

\section{Resultados}

En el análisis se describe la alteración de las variables económicas y cómo influyen en la economía peruana en el contexto macroeconómico en comparativa con cinco años seguidos de fluctuación respecto a los efectos relacionados con la COVID-19. 


\section{Tabla 1}

Estadísticos descriptivos de las fluctuaciones de las variables económicas

\begin{tabular}{lllllc}
\hline & N & Mínimo & Máximo & Media & Desviación \\
\hline $\begin{array}{l}\text { Tipo de cambio bancario promedio } \\
\text { Índice de la situación actual del }\end{array}$ & 56 & 3,21 & 3,51 & 3,3268 &, 07191 \\
$\begin{array}{l}\text { negocio } \\
\begin{array}{l}\text { Tasa de interés promedio activas y } \\
\text { pasivas en moneda nacional }\end{array}\end{array}$ & 56 & 12,30 & 17,73 & 15,1800 & 1,44868 \\
$\begin{array}{l}\text { Producto bruto interno } \\
\text { Reservas internacionales netas }\end{array}$ & 56 & $-39,9$ & 4,2 &, 707 & 8,6753 \\
\hline
\end{tabular}

Fuente: Elaboración propia

En la tabla 1 de estadística descriptiva observamos la variación en 5 años del tipo de cambio bancario promedio el cual fluctuó manteniéndose en un equilibrio de tres a uno con respecto al precio del dólar, en ese sentido el tipo de cambio interbancario promedio varió entre 3.21 y 3.51 soles, asimismo los índices de confianza empresarial variaron entre 21.5 y 61.0 siendo el punto de equilibrio 50 puntos, a su vez las tasas de interés se movieron entre $12.30 \%$ y $17.73 \%$ en promedio a su vez que el producto bruto interno decayó por la pandemia hasta caer en negativo $39.9 \%$ con un máximo acumulado en años anteriores de $4.2 \%$ de crecimiento continuo, respecto a las reservas internacionales se situó en el año 2016 en 57999 millones de dólares con un máximo en el año 2020 de 74782 millones de dólares esto debido a la fluctuación del tipo de cambio y la intervención del BCRP al convertir soles a dólares en el mercado cambiario como también a operaciones de depósitos de bancos comerciales entre otras estrategias.

En tal sentido la economía peruana se vio afectada por la pandemia mundial en los cinco indicadores económicos analizados las cuales hasta el día de hoy se encuentran en lenta recuperación por las expectativas de la llegada de la vacuna para inmunizar a la población y esta se vea recuperada a una próxima estabilización económica post-pandemia.

Se destaca en la tabla 1 la caída del PBI por factores de comercio exterior por consecuencia del cierre de fronteras como también de la paralización de la producción nacional, asimismo las expectativas de los empresarios cayeron a niveles históricos debido a las expectativas negativas y a la confusión de fechas de regresar a un escenario óptimo. 
Wuily Franz Trujillo Figueroa y Edmer Mendoza Briceño.

ISSN 2477-9024. Innova Research Journal (Mayo-Agosto, 2021). Vol 6, No. 2, pp. 240-254

Asimismo, las expectativas empresariales representada con el índice de la situación actual del negocio se vieron muy afectadas por las perspectivas de incertidumbre hacia lo que pasará a futuro por las restricciones implantadas por el gobierno peruano, como el caso de los negocios que no pueden funcionar normalmente y están a punto de cerrar por no encontrar un punto de equilibrio para ser rentables.

\section{Figura 1}

Variación de la tasa de interés

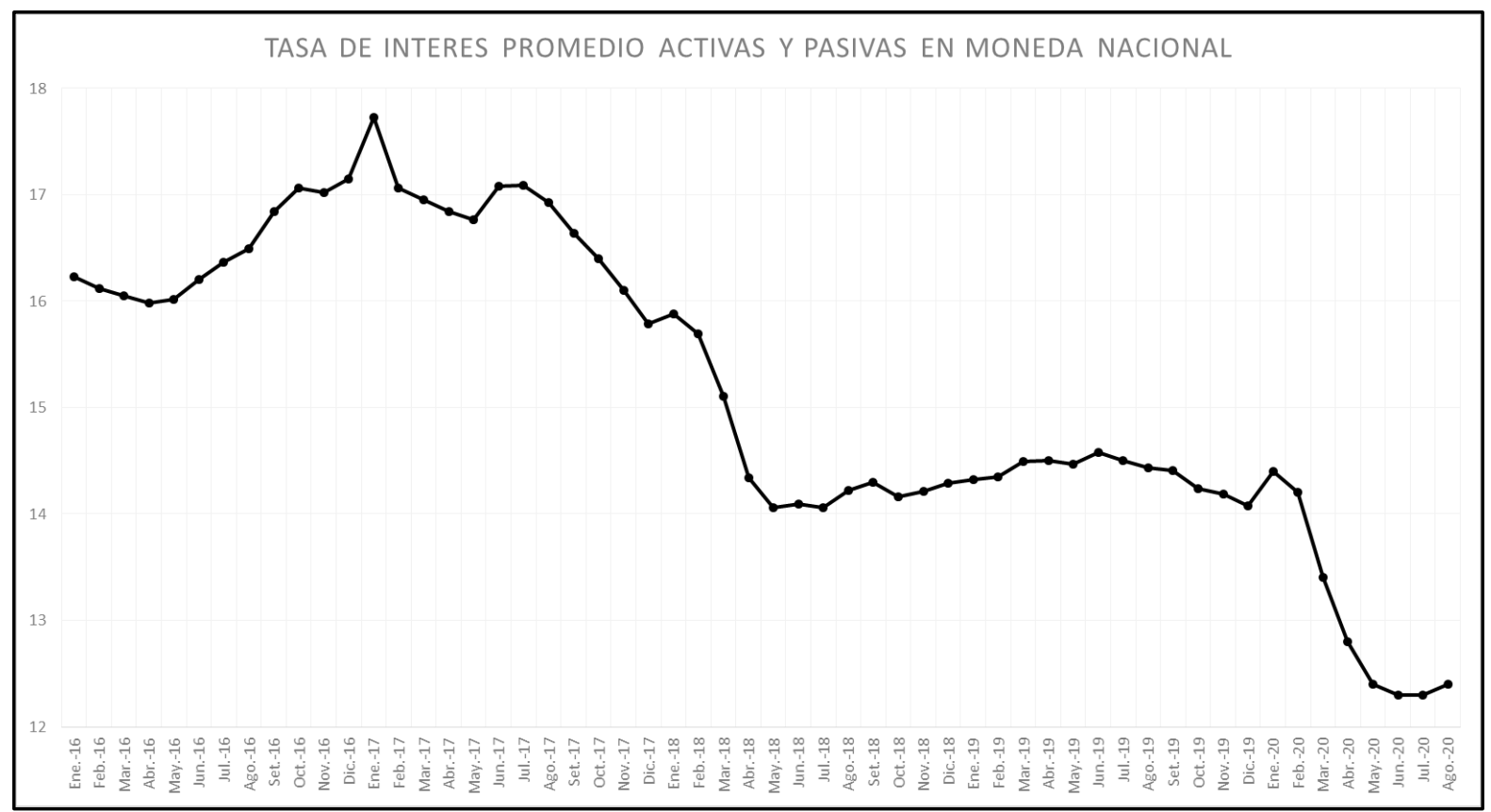

Fuente: Elaboración propia con datos del BCRP.

En la figura 1 se observa la tendencia de la tasa promedio activas y pasivas en moneda nacional (TPAPMN), se advierte que en el mes de junio del año 2020 con $12.30 \%$ el nivel más bajo y en enero del año 2017 la TPAPMN se ubicó en el nivel más alto con 17.73\%

Las tasas activas y pasivas la determinan las entidades financieras la cual realizan un cálculo según riesgo, tasa de interés promedio y diversos factores que influyen en el porcentaje final.

Se observa que el mes de junio del 2020 la tasa de interés promedio de activas y pasivas en un nivel bajo esto debido a la influencia de la tasa de referencia que se ubicó en 0.25 puntos porcentuales lo que originó una bajada en los intereses de los créditos. Asimismo, este estímulo provoco un crecimiento en el sector construcción ya que los consumidores accedieron a un crédito hipotecario con tasas de interés atractivas e importación de vehículos por el alza de créditos vehiculares atraídos por las tasas de interés por último el BCRP usa los instrumentos de política monetaria para buscar un punto de equilibrio en todos los indicadores económicos. 
En tal sentido, la tasa de interés en la economía peruana está influenciada por el riesgo, cuanto más riesgoso sea un agente deficitario la tasa de interés que le aplica una entidad financiera será más alta, la tasa de referencia es manejada por el BCRP según la política económica trazada ya sea expansiva con una baja tasa o una tasa alta cuando la economía se encuentra con riesgos de inflación u otros factores de dinamismo de dinero.

Durante los días de pandemia el gobierno peruano uso la estrategia mediante el programa de créditos reactiva Perú manejado por la banca privada para otorgar créditos con una tasa de interés baja en porcentaje a las pequeñas empresas para ayudar a reactivar el aparato productivo nacional.

\section{Figura 2}

\section{Variación del tipo de cambio}

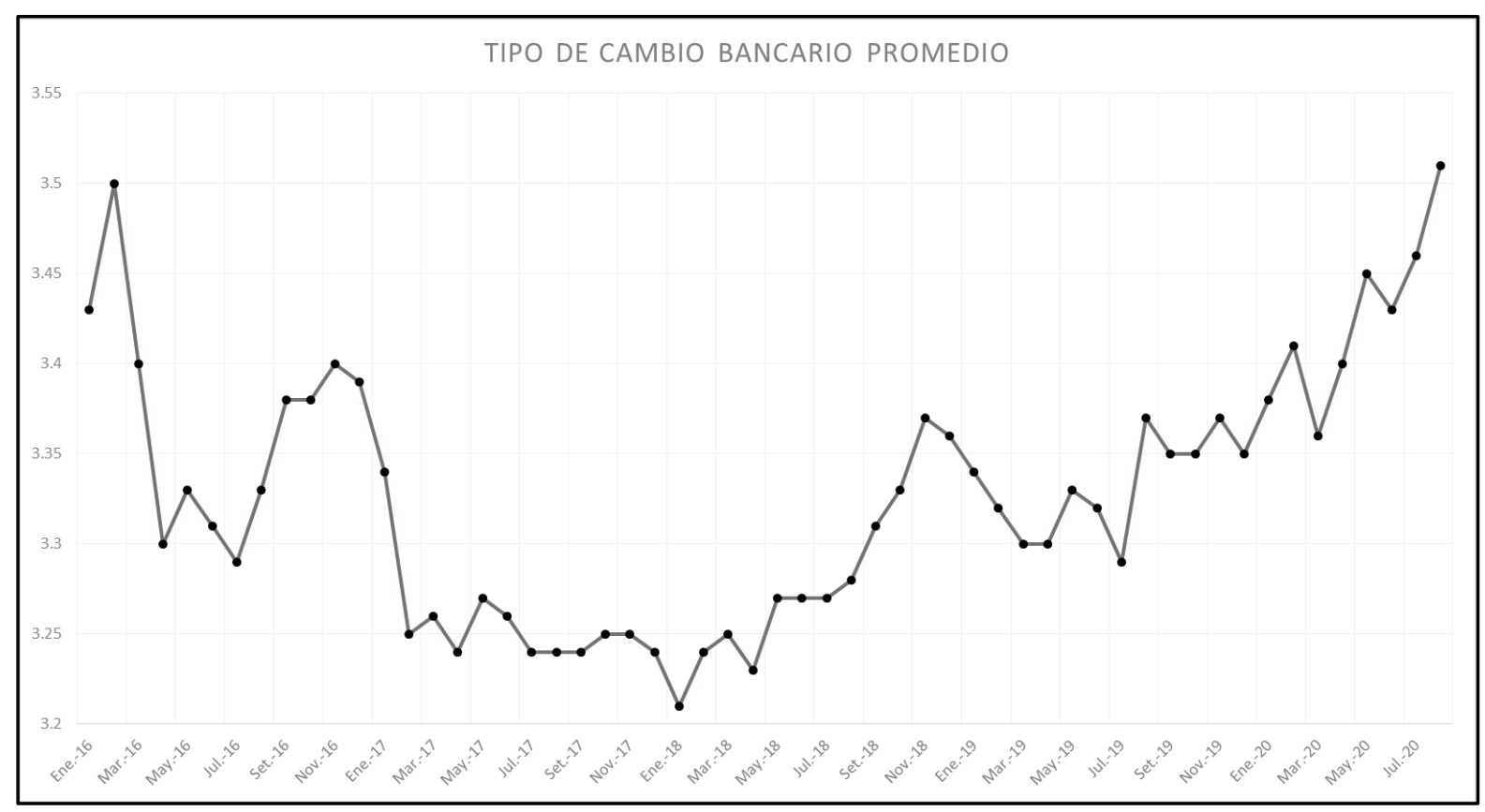

Fuente: Elaboración propia con datos del BCRP.

En la figura 2 se aprecia la tendencia del tipo de cambio bancario promedio (TCBP) evoluciona desde el año 2016 hasta el año 2020 y se observa en enero del año 2018 como el TCBP se ubicó en su nivel más bajo con 3.21 soles y llegando a su nivel más alto con 3.51 soles en julio del 2020.

El TC bancario lo manejan los bancos para operaciones con sus usuarios, las variaciones dependen de las cotizaciones diarias según la oferta y demanda y las intervenciones del BCRP que 
Wuily Franz Trujillo Figueroa y Edmer Mendoza Briceño.

ISSN 2477-9024. Innova Research Journal (Mayo-Agosto, 2021). Vol 6, No. 2, pp. 240-254

regula de manera constante para evitar variaciones bruscas y puedan afectar a todos los agentes especuladores en el mercado de divisas peruano.

El tipo de cambio bancario en el año 2016 se vio influenciada por los estímulos a la baja de la tasa de interés referencia de las economías desarrolladas y por consiguiente la fuga masiva de capitales atraídas por las economías emergentes de la región entre estas el Perú, además la nueva gestión gubernamental de los estados unidos decidió recortar las tasas impositivas lo que generó mayores tasas de interés en dólares a nivel global.

El TC informal se mueve en el mercado negro de divisas del Perú conocido también como dólar paralelo, mayormente este mercado esta alimentado por el vacío de la oferta y la demanda y el libre mercado monetario, la cual implica un riesgo por llevar efectivo de los jugadores especulativos, bajo esta premisa la COVID-19 trajo como consecuencia que los especuladores se refugien con dólares en gran parte de los días de pandemia.

\section{Figura 3}

Variación de las reservas internacionales netas

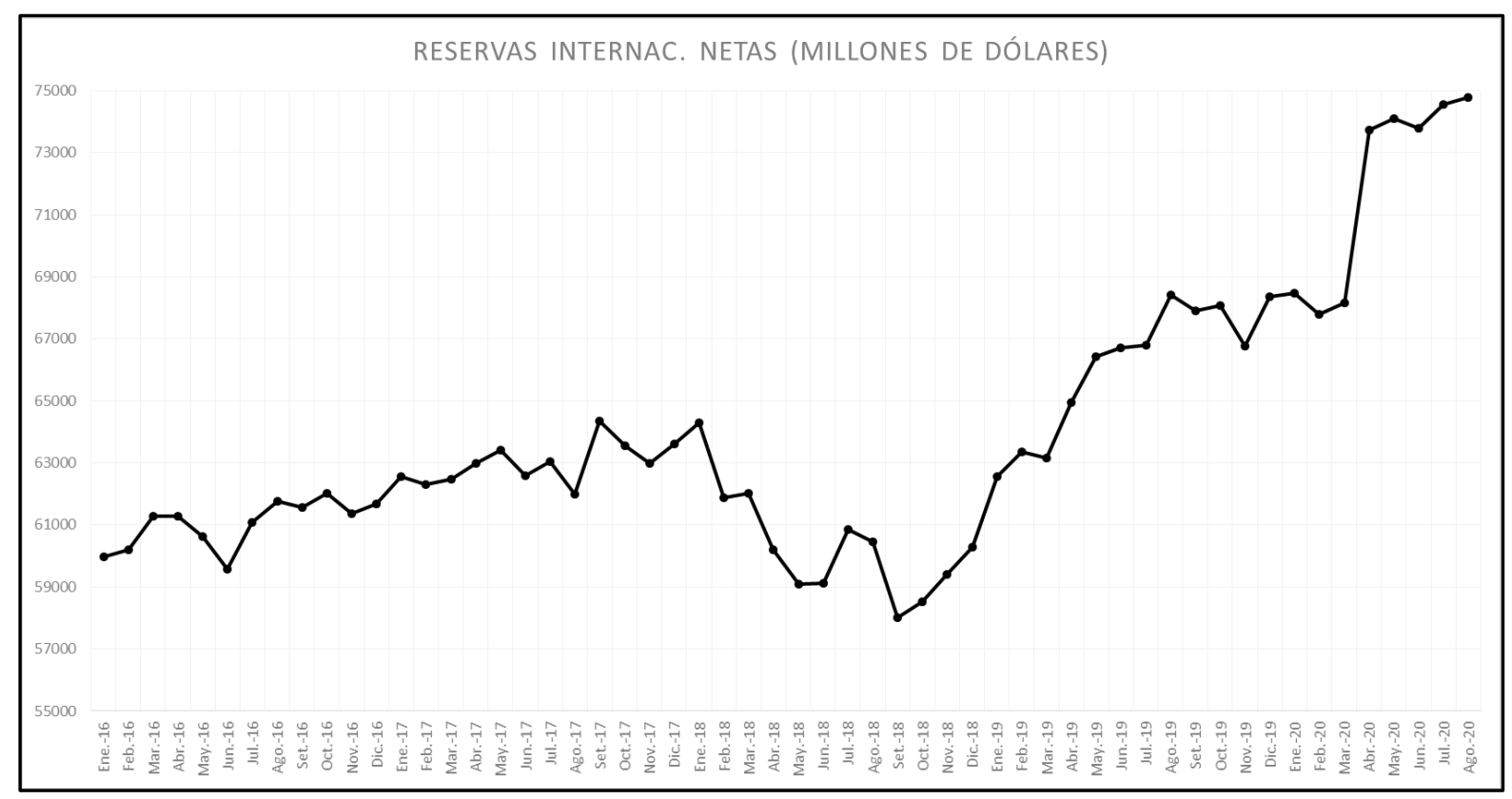

Fuente: Elaboración propia con datos del BCRP.

En la figura 3 se aprecia la evolución de las reservas internacionales netas en cinco años de análisis, con una mínima de 57,999 millones de dólares en el mes de setiembre del año 2018 y con un atesoramiento máximo de 74,782 millones de dólares en el mes de agosto del 2020 esto ocurrió por la constante intervención del BCRP al tipo de cambio que como se sabe intercambia soles por 
dólares para mantener la moneda estabilizada y sin cambios bruscos en la paridad cambiaria así también a otros factores de atesoramiento como los niveles de recaudación impositiva o los depósitos de bancos en las arcas del banco central.

Como se sabe las RIN son manejadas por el BCRP las cuales están conformadas por depósitos en el exterior, valores acumulados y las tenencias de plata y oro como principales dimensiones de análisis, las cuales son usadas por el ente emisor para las diversas estrategias de política monetaria que se manejan para afrontar cualquier alteración en la economía y está sucediendo en estos tiempos con la COVID-19.

En esa línea el BCRP utilizó una serie de estrategias de política monetaria para sobrellevar la crisis originada por la pandemia con el respaldo de las reservas internacionales.

Asimismo, el Perú se encuentra en estos momentos con una de las reservas más grandes en comparativa con los países de la región la cual ayudará a tener un respaldo en liquidez para la reactivación económica futura y cubrir diversos riesgos originados por la pandemia mundial.

\section{Figura 4}

\section{Variación del producto bruto interno}

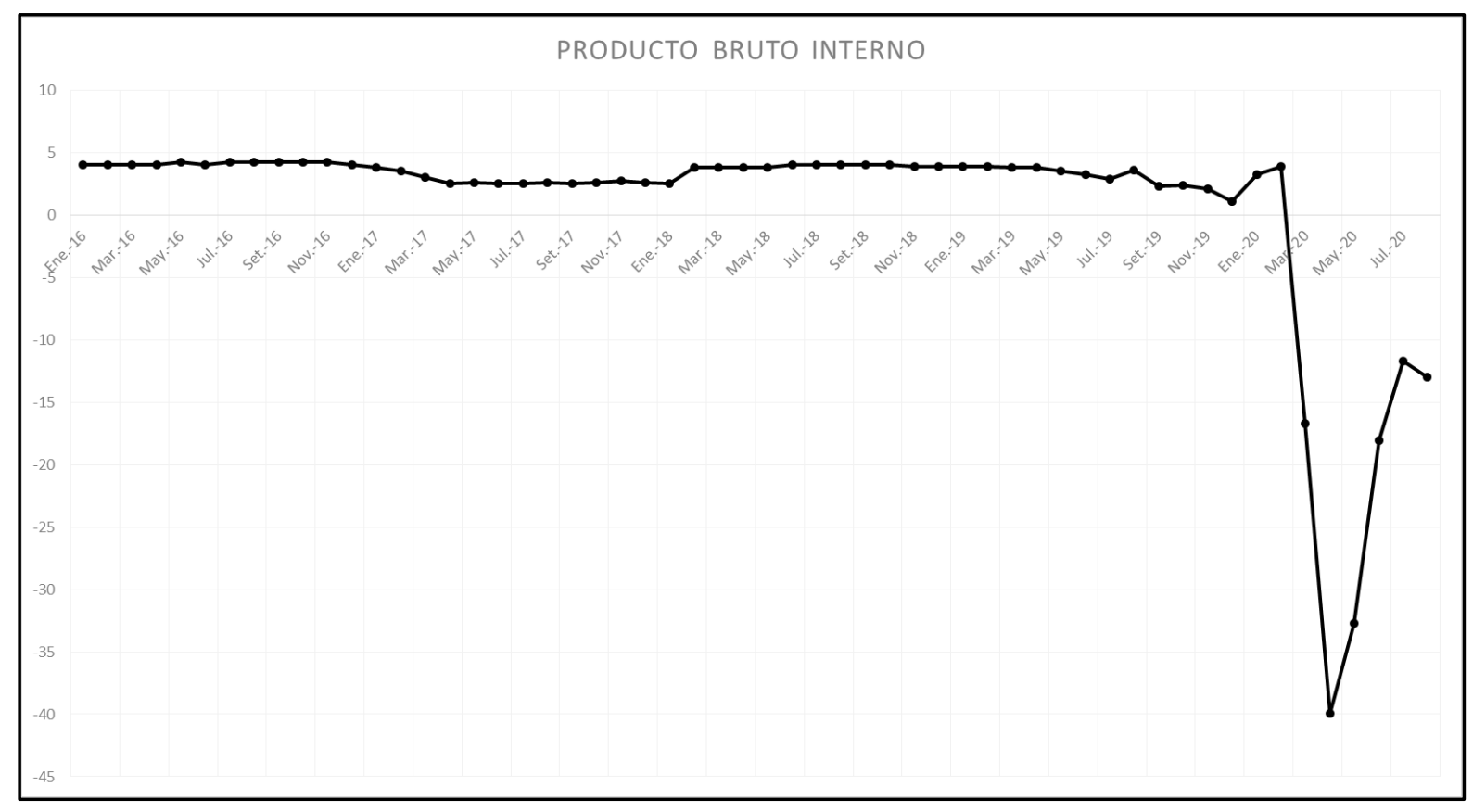

Fuente: Elaboración propia con datos del BCRP.

En la figura 4 se observa la variación de la tendencia del PBI en cinco años de análisis donde el mes de mayo de año 2020 se reporta una caída negativa de -39.9 puntos porcentuales, 
Wuily Franz Trujillo Figueroa y Edmer Mendoza Briceño.

ISSN 2477-9024. Innova Research Journal (Mayo-Agosto, 2021). Vol 6, No. 2, pp. 240-254

asimismo se observa en el mes de enero del 2020 la economía peruana se situaba con un crecimiento sostenido de $4.2 \%$ la cual se mantuvo constante hasta la aparición de la COVID-19 en la economía mundial que hizo efectos negativos en al menos todos los países del mundo.

En el Perú el PBI se mantuvo con variabilidad estable y un crecimiento promedio de más de dos puntos porcentuales anuales hasta la llegada del flagelo del nuevo coronavirus, como se sabe el PBI es un principal indicador de medición de la economía de los bienes y servicios finales a modo contable en el caso peruano esta medición lo realiza el INEI.

En esa línea las exportaciones cayeron en $40.3 \%$ y las importaciones en $31.3 \%$ el gasto de consumo de familias cayó en $22.1 \%$, el gasto de consumo final de gobierno se contrajo en $3.2 \%$ como también la inversión bruta fija en $57.7 \%$, las actividades extractivas en $20.9 \%$ de transformación en $44.5 \%$ y de servicios en $28.3 \%$ todos estos indicadores en porcentajes negativos.

Además, la economía peruana venía de un crecimiento ininterrumpido de 21 años seguidos y nunca antes con un resultado negativo como lo sucedido por la pandemia mundial, si bien es cierto en los últimos meses ya se observa la recuperación lenta del PBI y con las expectativas de mejorar el índice económico con la llegada de la vacuna para inmunizar a la población del virus.

\section{Figura 5}

Variación de las expectativas empresariales

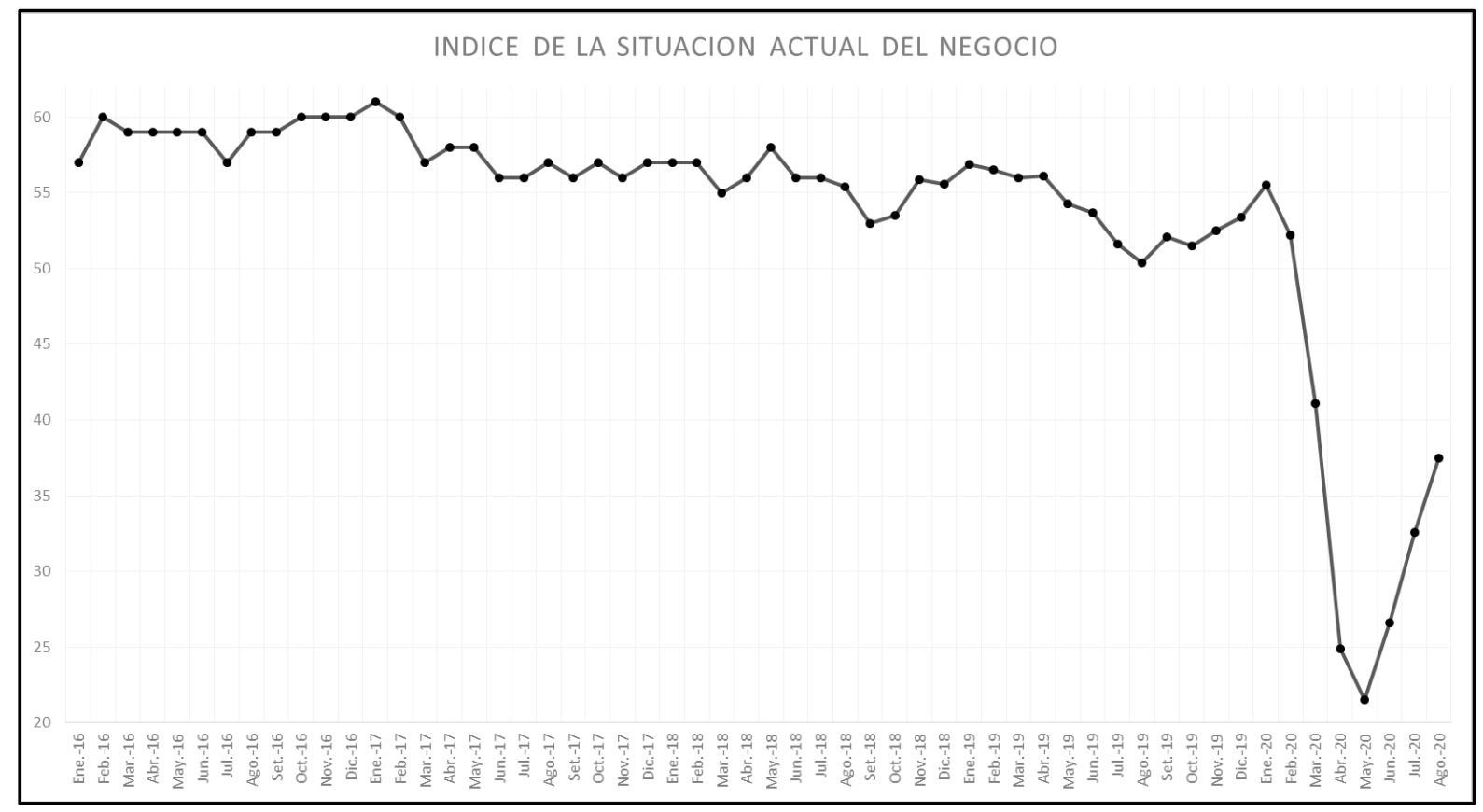

Fuente: Elaboración propia con datos del BCRP. 
En la figura 5 se examina la tendencia de las expectativas empresariales en la situación actual del negocio, se observa en el año 2019 con 21.5 puntos el nivel más bajo en las encuestas de percepción y el año 2014 el nivel más alto con 61.0 puntos.

El índice la de situación actual del negocio se da como resultado de encuestas de percepción a empresarios peruanos de cómo aprecian el rubro de su inversión en relación a las diversas situaciones de entorno económico, estas encuestas las realiza el BCRP mensualmente y nos da el grado de expectativas empresariales la cual tiene como punto de equilibrio 50 puntos.

En tal sentido los 5 años descritos la situación actual del negocio ha sido bastante variable por el entorno económico en varios aspectos ya sea la inflación, el PBI, el riego país, etc. Que influyen en los inversionistas al momento de colocar capital en el mercado peruano.

El índice de las expectativas es elaborado por el BCRP, este índice nos da una visión del grado de confiabilidad de los empresarios encuestados a su proyección de expectativas a un mes en adelante del mes analizado de cómo ellos piensan de cómo será la demanda de los productos que ofrecen en el mercado ya sea de capitales, inmobiliario, etc.

Asimismo, los índices de expectativas empresariales durante la pandemia cayeron a mínimos históricos con 21.5 puntos la cual se fue recuperando por la llegada de la vacuna y con las expectativas positivas de poder descender el efecto del coronavirus.

\section{Conclusiones y recomendaciones}

En los 5 años del análisis se observó que el tipo de cambio bancario promedio se ubicó entre 3.21 y 3.51 soles, se observa que la volatilidad de la paridad cambiaria fluctuó a niveles manejables no se advirtió cambios bruscos de depreciación de moneda, del sol respecto al dólar y esto es positivo para las inversiones futuras por no tener un alto riesgo de paridad de moneda.

Las expectativas de la economía se ubicaron entre 21.5 y 61 puntos se observa que desde un horizonte de punto de equilibrio de 50 puntos normalmente, examinamos demasiada fluctuación de la percepción de los empresarios con respecto al panorama futuro de la economía, se recomienda establecer medidas de política económica de reactivación.

Observando la tasa de interés promedio activas y pasivas en moneda nacional que se situó entre $12,30 \%$ y $17.73 \%$ se percibe que los intermediarios financieros están aplicando tasas de interés muy elevadas y esto se refleja en los índices de confianza empresarial, se recomienda establecer tasas atractivas a niveles bajos para darle velocidad a las inversiones respecto a los

niveles de endeudamiento sabiendo que la tasa de interés de referencia de la política monetaria determinada por el BCRP se ubica en $0.25 \%$. 
Wuily Franz Trujillo Figueroa y Edmer Mendoza Briceño.

ISSN 2477-9024. Innova Research Journal (Mayo-Agosto, 2021). Vol 6, No. 2, pp. 240-254

Asimismo, se percibe que se debe poner énfasis en el producto bruto interno y aplicar nuevas estrategias en política económica para conservar los niveles de crecimiento económico como se registró en promedio de $4.2 \%$ antes de la pandemia.

Respecto a las reservas internacionales se debería continuar con las estrategias de política monetaria, como vemos en el análisis, las RIN se situaron en 74782 millones de dólares en la actualidad que contribuirá a afrontar futuros escenarios post COVID-19.

\section{Referencias Bibliográficas}

Baker, S., Bloom, N., Davis, S., \& Terry, S. (2020). COVID induced economic uncertainty. Institute for economic policy research, 20(14).

Barrutia, I., Sanchez, R., \& Silva, A. (2021). Consecuencias económicas y sociales de inamovilidad humana bajo COVID-19 caso de estudio Perú. Lecturas de economía (94). https://doi.org/10.17533/udea.le.n94a344397

Bartik, A., Bertrand, M., Cullen, Z., Glaeser, E., \& Luca, M. (2020). The impact of COVID-19 on small business outcomes and expectations. Proceedings of the national academy of sciences, 117(30), 17656-17666. https://doi.org/10.1073/pnas.2006991117

BCRP. (2011). Glosario de términos económicos. Lima, Perú: Banco central de reserva del Perú. Beckmann, J., \& Czudaj, R. (2017). Exchange rate expectations and economic policy uncertainty. European journal of political economy, 47, 148-162. https://doi.org/10.1016/j.ejpoleco.2016.06.003

Bedford, J., Enria, D., Giesecke, J., \& Heymann, D. (2020). COVID-19: towards controlling of a pandemic. The lancet, 395, 1015-1018. https://doi.org/10.1016/S0140-6736(20)3067-5

Bernal, C. (2020). Metodología de la investigación. Bogotá, Colombia: Pearson.

Bonaccorsi, G., Pierri, F., Cinelli, M., Flori, A., \& Galeazzi, A. (2020). Economic and social consequences of human mobility restrictions under COVID-19. Proceedings of the national academy of sciences, 117(27), 15530-15535. https://doi.org/10.1073/pnas.2007658117

Boumans, D., Link, S., \& Sauer, S. (2020). COVID-19: the world economy needs a lifeline-but which one? Econpol policy brief, 4(27).

Deb, P., Furceri, D., D.ostry, J., \& Tawk, N. (2020). The economic effects of COVID-19 cointainment measures. International monetary fund, 1-44.

Delgado, A. (2020). Implicancias de la suspensión perfecta de labores en el Perú frente al impacto económico se la COVID-19. Revista iberoamericana de derecho del trabajo y de la seguridad social, 2(4), 55-65.

Dulzaides, M., \& Molina, A. (2004). Análisis documental y de información: dos componentes de un mismo proceso. Acimed, 12(2).

Hernández, R., Fernández, C., \& Baptista, M. (2014). Metodología de la investigación. DF, Mexico: McGraw-Hill. 
Huamán, J. (2021). Impacto económico y social de la COVID-19 en el Perú. Revista de ciencias e investigación, 2(1), 31-42.

Lippi, G., Henry, B., Mattiuzzi, C., \& Bovo, C. (2020). The death rate for COVID-19 is positively associated with gross domestic products. Acta biomed, 91, 224-225. https://doi.org/10.1016/S2214-109X (20)30068-1

Mckibbin, W., \& Roshen, F. (2020). The economic impact of COVID-19. Economics in the time of covid-19, 1-45.

Ñaupas, H., Mejia, E., Novoa, E., \& Villagómez, A. (2011). Metodología de la investigación científica y asesoramiento de tesis. Lima, Perú: Editorial San Marcos.

Pascal, P., \& Simon, Z. (2020). Are banks exposed to interest rate risk? FRBSF economic letter, $16,1-5$.

Peña, T., \& Pirela, J. (2007). La complejidad del análisis documental. Información, cultura y sociedad, 16, 55-81.

Rivot, S. (2020). Keynes treatment of dynamics and stability in a monetary economy: the role played by expectations from the tract on monetary reform to the general theory. The european journal of the history of economic thought, 1-26.

Sanchez, H., Reyes, C., \& Mejia, K. (2018). Manual de términos en investigación científica, tecnológica y humanística. Lima, Perú: Ediciones Universidad Ricardo Palma.

Singh, G. (2020). COVID-19: reserves to the rescue. Ideas for India, 4, 21-42. 